\title{
A new grouping measure for evaluation of machine-component matrices
}

\author{
H. SEIFODDINI $\dagger$ and M. DJASSEMI +
}

The machine-component matrix is the main input to most machine-component grouping models used in cellular manufacturing. A nurnber of measures have been developed for performance evaluation of machinc-component grouping algorithms. In this paper, the relationship between these measures and the performance of the corresponding cellular manufacturing system is evaluated and a new grouping measure is developed which is more consistent in predicting the suitability of a manufacturing system for cellular manufacturing.

\section{Introduction}

The machine-component matrix is the main input to most machine component grouping models. It is an $\mathrm{M} \times \mathrm{N}$ matrix with zero/one entries. The presence or absence of a 'onc' entry in row $i$ and column $j$ of the matrix indicates the operation, or lack of operation, of part $j$ on machine $i$, respectively. When natural machinecomponent groups exist in a production system the rearaangement of parts and machines in the corresponding machine-component matrix generates a block diagonal form in which 'one" entries are concentrated in blocks along the diagonal of the matrix (Burbidge 1977). These blocks correspond to machine-component groups which are used to form a cellular manufacturing system. An initial machinecomponent matrix and its final block diagonal form are presented in Fig. 1.

A number of algorithms have been developed to identify machine-component groups for ccllular manufacturing. Some of these algorithms form machine-component groups by permutations on rows and columns of the machine-component matrix (King and Nakornchai 1982, Chan and Milner 1982). Some other algorithms use clustering techniques from the field of numcrical taxonomy to group machines into machine cells and components into part-families (McAuley 1972, Carrie 1973, Seifoddini and Wolfe 1986). The results of all of these algorithms can be presented in a block diagonal form. There arc several studies that compare these algorithms (Mosier 1989, Chu and Tsi 1991, Miltenburg and Zhang 1991).

A complete block diagonal matrix in which mutually independent machinecomponent groups can be identificd is ideal for the successful development of a cellular manufacturing system. As the number of parts requiring operations in more than one machine cell (exceptional parts) increases, the effectiveness of the corresponding cellular manufacturing system decreases. This is due to intercellular material handling costs associated with exceptional parts and the necessary adjustment in the cellular manufacturing system to accommodate the processing of these

†lndustrial and Systems Engineering, University of Wisconsin-Milwaukee, EMS Building, PO Box 784, Milwaukee, WI 53201, USA.

¡Department of Industrial Studies, University of Wisconsin-Plattville, USA. 


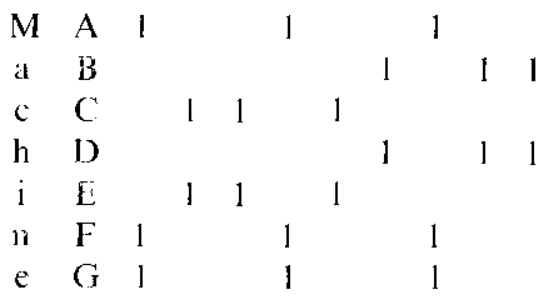

$\begin{array}{lllll}\text { M } & \text { C } & 1 & \text { I } & \text { l } \\ \text { a } & \text { E } & 1 & 1 & \text { l } \\ \text { c } & \text { G } & & & \\ \text { h } & \text { A } & & & \\ \text { i } & \text { F } & & & \\ \text { n } & \text { B } & & & \\ \text { c } & \text { D } & & & \end{array}$

$\begin{array}{llllll}1 & 1 & 1 & & & \\ 1 & 1 & 1 & & & \\ 1 & 1 & 1 & & & \\ & & & 1 & 1 & 1 \\ & & & 1 & 1 & 1\end{array}$

Figure 1. (a) Initial machinc-component matrix (b) Block diagonal foiri.

exceptional parts (Seifoddini 1989). Since the number of exceptional parts is a function of the number of off-diagonal 'one' cntries in the machine component matrix, the structure of the final machine-component matrix significantly afects the effectiveness of the corresponding collular manufacturing system. For this reason. a number of grouping measures have been developed to evaluate the efficiency of block diagonal forms including: bond energy (BE) (McCormick et al. 1972), grouping efficiency (GE) (Chandrasekharan and Rajagopalan 1987), grouping efficacy (GC) (Kumar and Chandrasekharan 1990), and grouping capability index (GCI) (Hsu 1990). No study has been done to determine the relationship between these measures and the performance of the corresponding cellular manufacturing system.

In this paper, the effectiveness of the existing measures in predicting the performance of a cellular manufacturing system is evaluated and a new grouping measure will be developed which more consistently determines the efficiency of a thock diagonal form for developing a cellular manufacturing system.

\section{Background}

One of the first algorithms for converting a binary matrix into a block diagonal form uses a grouping measure called 'bond encrgy' (BE) (McCormick et al. 1972). This measure is calculated as follows:

$$
\mathrm{BE}-\sum_{i=1}^{m} \sum_{j=1}^{n-m} d_{i j}\left[d_{i, j+1}+d_{i, j}+d_{i-1, j}+d_{i-1, j}\right]
$$

where

$$
\begin{aligned}
m & =\text { number of rows in the binary matrix } \\
n & =\text { number of columns in the binary matrix } \\
d_{i j} & =\text { a binary (zero or one) entry in row } i \text { and column } j \text { of the binary matrix } \\
d_{0, j} & =d_{m, !}, j=d_{i, 0}=d_{i, n+1}-0
\end{aligned}
$$

Since this measure is usually at its maximum value when the desirable block diagonal form is achieved, it can be used for the evaluation of machine-component matrices.

Grouping efficiency (GE) was developed to evaluate the efficiency of block diagonal matrices (Chandrasekharan and Rajagopalan 1987). It is defined as:

$$
\mathrm{GE}=q E_{1}+(1-q) E_{2}
$$


where

$$
\begin{aligned}
\mathrm{E}_{1} & =\frac{\text { Number of ones in the diagonal blocks }}{\text { Total number of elements in the diagonal blocks }} \\
\mathrm{E}_{2} & =\frac{\text { Number of zeros in the off-diagonal blocks }}{\text { Total number of elements in the off-diagonal blocks }} \\
q & =\text { A weighting factor ranging between zero and one }
\end{aligned}
$$

The selection of $q$ for grouping efficiency is arbitrary and according to the designer of the measure (Kumar and Chandrasekharan 1990) the range of values for this measure is limited to $75-100 \%$. That means even when there are a large number of exceptional parts, the grouping efficiency of the machine-component matrix is at least 0.75 .

To overcome the problems of the selection of $q$ and the limited range of grouping efficiency, another grouping measure has been developed. This measure is grouping efficacy (GC) and is defined as (Kumar and Chandrasekharan 1990):

$$
\mathrm{GC}=q \cdot \mathrm{E}_{1}+(1-q) \mathbf{E}_{2}
$$

in which

$$
\begin{aligned}
q & =\sum_{r=1}^{\mathrm{K}} \mathrm{M}_{r} \cdot \mathrm{N}_{r} / m \cdot n \\
\mathrm{E}_{\mathrm{l}} & =\frac{e_{o}}{\sum_{r=1}^{\mathrm{K}} \mathrm{M}_{r} \cdot \mathrm{N}_{r}} \\
\mathrm{E}_{2} & =1-\frac{e_{o}}{m \cdot n-\sum_{r=1}^{\mathrm{K}} \mathrm{M}_{r} \cdot \mathrm{N}_{r}}
\end{aligned}
$$

where

$\mathrm{K}=$ number of blocks

$\mathbf{M}_{r}=$ number of rows in $r$ th block

$\mathrm{N}_{r}=$ number of columns in $r$ th block

$e_{o}=$ number of ones in the diagonal blocks

$m$ and $n$ as defined before.

Grouping efficacy overcomes the problem of grouping efficiency by incorporating the size of the matrix into the calculation of the measure. It also provides a quantitative basis for calculating the weighting factor, $q$.

In a study by Hsu (1990), it was shown that neither group efficiency nor group efficacy is consistent in predicting the performance of a cellular manufacturing system based on the structure of the corresponding machine-component matrix.

Grouping capability index (GCI) (Hsu 1990), is defined as:

$$
\mathrm{GCI}=1-\frac{e_{0}}{e}
$$

where

$e_{0}=$ number of exceptional elements in the machine-component matrix

$e=$ total number of one entries in the machine-component matrix 
Contrary to the previous two measures, GCl excludes zero entries from the calculation of grouping efficiency.

In addition to machining requirements of parts which are given in the machinecomponent matrix, many other production factors such as production volume and processing times of opcrations affect the performance of a cellular manufacturing system. None of the previously discussed measures consider these factors. In this paper, a new grouping measure is defined which is based on machining requirements of parts, production volume and processing times of operations.

\section{New grouping measure}

The new grouping incasure called 'quality index' (QI) is calculated as the ratio of the intercellular workload to the total plant's workload. The intercellular workload (ICW) is defined as:

$$
\mathrm{ICW}=\sum_{i=1}^{\mathrm{K}}\left[\sum_{i=1}^{\mathrm{M}} X_{i l}\left(\sum_{i=1}^{\mathrm{N}}\left(\mathrm{l}-\mathrm{y}_{j l}\right) \mathrm{Z}_{i j} \cdot \mathrm{V}_{j} \cdot \mathrm{T}_{i j}\right)\right]
$$

where

$$
\begin{aligned}
& \mathrm{X}_{i f}=\begin{array}{l}
1 \text { if machine } i \text { is assigned to machine cell / } \\
0 \text { otherwise }
\end{array} \\
& \mathrm{Y}_{j l}-\begin{array}{l}
1 \text { if part } j \text { is assigned to machine cell } / \\
0 \text { otherwise }
\end{array} \\
& Z_{i j}=\begin{array}{ll}
1 & \text { if part } j \text { has operations on machine } i \\
0 & \text { otherwise }
\end{array} \\
& \mathrm{V}_{i}-\text { production volume for part } j \\
& \mathrm{~T}_{i j} \text { - processing time of part } j \text { on machine } i
\end{aligned}
$$

$\mathrm{K}, \mathrm{M}$, and $\mathrm{N}=$ number of machine cells, machines. and parts, respertively

The total plant workload (PW) can be calculated as:

$$
\mathrm{PW}-\sum_{i=1}^{\mathrm{M}} \sum_{j=1}^{\mathrm{N}} Z_{i j} \cdot \mathrm{V}_{i} \cdot \overline{\mathbf{I}}_{i j}
$$

where

$\mathrm{M}, \mathrm{N}, \mathrm{Z}_{i j}, \mathrm{~V}_{j}$ and $\mathrm{T}_{i j}$ are as defined before.

The quality indicx (Qi) for a block diagonal machine-conponent mairix is calculated as:

$$
\mathrm{QI}=\mathrm{I}-\frac{\mathrm{ICW}}{\mathrm{PW}}
$$

By incorporating the production volume and processing times in the ealculation of grouping measure, QI hat the potential for significantly improving the cvaluation of block diagonal form. This is due to the fact that production volume and processing time are wo inportant lactors affecting the perfomance of the suldar manufactioing system. As a result, QI is more closely related to the performance of the cellular ninanufacturifig systen than all other giouping measures which solely use the data in the machinc-component matrix. 


\section{Comparison of grouping measures}

A simulation model is developed for the performance evaluation of cellular manufacturing systems. The performance evaluation is the basis for the comparison of the five different grouping measures defined here. It is used to determine which measure more accurately predicts the performance of a cellular manufacturing system by evaluating the corresponding machine-component matrix. The efficiency of a machine-component matrix is calculated using different grouping measures. The performance of the corresponding cellular manufacturing system is then determined using performance measures such as average flow time and average in-process inventories. Finally, based on the relationship between the value of the grouping measure of the machine-component matrix and the performance of the corresponding cellular manufacturing system, the effectiveness of each grouping measure is evaluated.

The algorithmic form of the procedure for the evaluation of grouping efficiency measures is as follows:

Step (1) Choose a machine-component matrix and convert it into a block diagonal form using one of the existing machine-component grouping algorithms such as ROC (King and Nakoranchai 1982), DCA (Chan and Milner 1982), or SCM (Seifoddini and Wolfe 1986).

Step (2) Calculate the efficiency of the block diagonal form using grouping measures including: bond energy (BE), grouping efficiency (GE), grouping efficacy (GC), grouping capability index (GCI), and quality index (QI).

Step (3) Develop a simulation model of the cellular manufacturing system corresponding to the block diagonal form obtained in Step 1.

Step (4) Estimate the average flow lime and average in-process inventories for the cellular manufacturing system using the simulation model developed in Step 3.

Step (5) Repeat Steps 1-4 for a number of different situations and evaluate the relationship between each grouping measure and the performance of the corresponding cellular manufacturing system.

This procedure will be used in the following section to compare the existing grouping measures.

The simulation model for the performance evaluation of the cellular manufacturing system has the following characteristics:

- The machine-component matrix used to form the cellular manufacturing system is given in Fig. 2.

- The time between orders for parts is exponentially distributed with the mean of 10 hours. The size of each order has a uniform distribution between $1 \cdot 10$ parts.

- The processing and set-up times are deterministic (data from a real shop is used).

- Set-up times are sequence dependent. Set-up times for parts within a partfamily are half of those for parts from two different part-families. This ratio decreases to $0 \cdot 1$ when two identical parts visit a machine in row.

- The processing and transportation of parts between machine cells is done in batches. Within a machine cell, parts are transferred to the next machine as soon as they are processed on the current machine. 


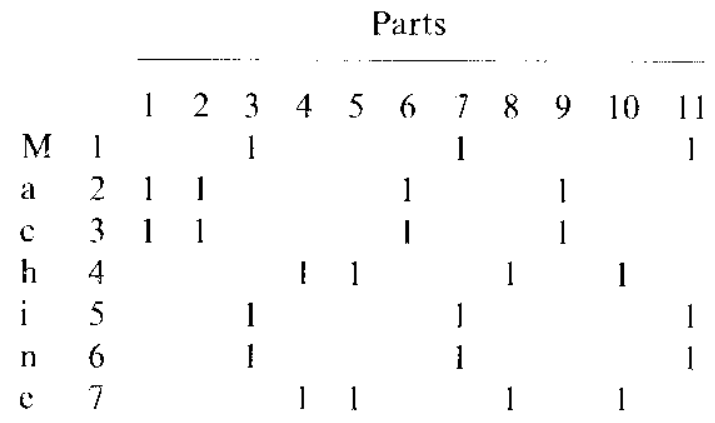

(a) Initial machine-component matrix.

\begin{tabular}{cccccccccccccc} 
& \multicolumn{11}{c}{ Part Families } \\
& & 1 & 2 & 6 & 9 & 3 & 7 & 11 & 4 & 5 & 8 & 10 \\
$\mathrm{M}$ & 2 & 1 & 1 & 1 & 1 & & & & & & & \\
$\mathrm{a}$ & 3 & 1 & 1 & 1 & 1 & & & & & & & \\
$\mathrm{c}$ & 1 & & & & & 1 & 1 & 1 & & & & \\
$\mathrm{~h}$ & 5 & & & & & 1 & 1 & 1 & & & & \\
$\mathrm{i}$ & 6 & & & & & 1 & 1 & 1 & & & & \\
$\mathrm{n}$ & 4 & & & & & & & & 1 & 1 & 1 & 1 \\
$\mathrm{c}$ & 7 & & & & & & & & 1 & 1 & 1 & 1
\end{tabular}

(b) Block diagonal form.

Figure 2. Machine-component matrix used in simulation model.

- The average flow time and in-process inventories are used as the performance measures for the cellular manufacturing system.

The simulation model is used to estimate the two performance measures: average flow time and average in-process inventorics. A warm-up period of six months is used to minimize the effects of the transient period. A common graphical method known as replication/deletion method was used to determine the length of warm-up period. Visual cxamination of the graph shows that system performance reaches the steady state in six months. Therefore a warm-up period equal to six months was considered and all observations recorded during that period were truncated.

The model is simulated over a period of one year beyond the warm up period. $\Lambda$ method called batching the data is suggested in simulation texts as a techrique for constructing a point estimate and confidence interval for the mean. Based on batching method the data generated during steady state condition are divided into $n$ batches of size $k$. In this study the data were divided into 20 batches of size 13 days (equal almost to onc year exchuding holidays). It is reasonable to divide the observations from a single long simulation run into 10 to 20 batches (Law and Kelton 1982).

In order to minimize the variance of the mean of differences common random number streams were employed across the simulation models. That is, the same stream was used to generate the time between orders and size of orders for all versions. 


\section{Analysis of results}

T'o evaluate the relationship between the values of grouping measures: $\mathrm{BE}, \mathrm{GE}$, GC, GCI and QI, and the performance of the cellular manufacturing system, five different versions of the machine-component chart in Fig. 2 are used in the simulation experiment. Variations from one version to another are limited to changes in the number of exceptional parts and their processing requirements.

In the following sections, each version of the machine-component matrix and the associated simulation results are presented. In addition, a frequently cited machinecomponent matrix in the literature will be used to calculate the efficiency measures and to estimate (using simulation) the performance of the corresponding cellular manufacturing system. This provides a common basis for comparing the results of the study with the existing results.

In version 1 (Fig. 3(a)), there are three machine cells with no exceptional parts. As expected, in this case, all grouping measures yield $100 \%$ efficiency. The values of these measures and the corresponding simulation results are given in Fig. 3(b). It should be noted that all grouping measures except BE are in the scale of $0-1 \cdot 0$. In order to present the BE in the same scale, the value of BE for the ideal machine-component matrix is considered equal to $1 \cdot 0$. 'Then the value of $\mathrm{BE}$ for other versions of the matrix is divided by the value of the ideal matrix. For example, assume the ideal matrix yields $\mathrm{BE}$ equal to 64 and another version of the matrix yields BE equal 59 . Then the adjusted value of $\mathrm{BE}$ for the ideal matrix is $64 / 64=1 \cdot 0$, and for the latter matrix is $59 / 64=0.92$.

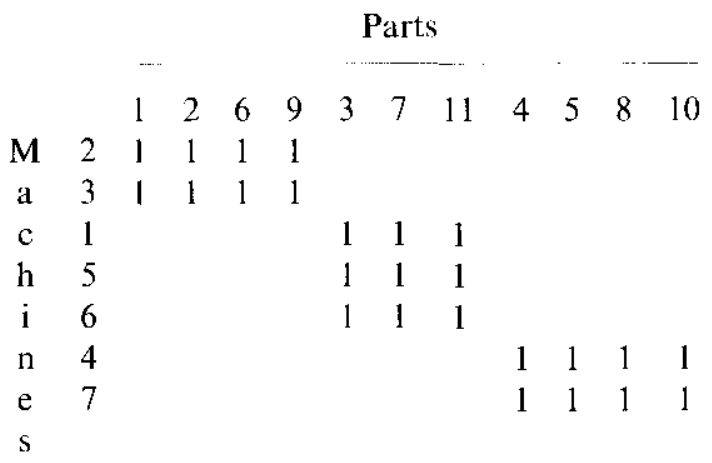

(a) Block diagonal form.

\begin{tabular}{|c|c|c|c|c|}
\hline \multicolumn{5}{|c|}{ Matrix efficiency } \\
\hline $\mathrm{BE}$ & $\mathrm{GE}$ & $\mathrm{GC}$ & $\mathrm{GCI}$ & QI \\
\hline \multicolumn{5}{|c|}{ Shop performance } \\
\hline \multicolumn{2}{|c|}{$\begin{array}{c}\text { Flow time } \\
35\end{array}$} & \multicolumn{3}{|c|}{$\begin{array}{c}\text { Work-in-progress } \\
19\end{array}$} \\
\hline
\end{tabular}

(b) Grouping measures and simulation results.

Figure 3. Version 1 of the machine-component matrix. 


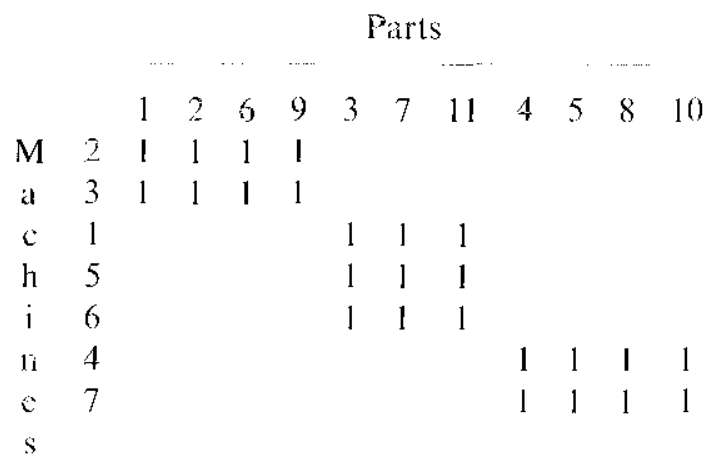

(a) Block diagonal formi.

\begin{tabular}{ccccc}
\hline \multicolumn{5}{c}{ Matrix elficiency } \\
BE & GE & GC & GCl & QI \\
0.93 & 0.97 & 0.92 & 0.96 & 0.99 \\
\multicolumn{4}{c}{ Shop perlormance } \\
Hlow time & Work-in-progress \\
38 & & 19 \\
\hline
\end{tabular}

(b) Grouping measures and simulation results.

Figure 4. Version 2 of the machine-compolient matrix.

Version 2 (Fig. $4(a)$ ) is slightly different from version 1 . Part 1 , in this version, has onc operation outside machine cell 1 and becomes an exeptional part. Since this part has the minimum workload content (processing time $\times$ volume), its effect on performance of the cellular manufacturing is minimal. This is reflected in simulation results in which the average flow time is marginally higher than in version 1 with no change in the average in-process inventories. All giouping measures are lower as presented in Fig. $4(h)$.

In version 3 (Fig. 5(a)), part 8 becomes an exceptional part (by switching one of its operations from nachine 4 to machitie 3 ). This part has the highest workload cortent and the change of its status should significantly change the performance measure: as indicated by simulation results (Fig. $5(h)$ ). Only one of the grouping measures, QI, reflects the changes dramatically. QI decreases from 0.99 in version 2 to 0.90 in this version. BE decreases from 0.93 to 0.90 . All other measures are insensitive to changes introduced in version 3 and remain the same (Fig. $5(b)$ ).

In version 4 (Fig. $6(a)$ ), there are two exceptional parts (parts I and 5). These are parts with the lowest workload contents, and as expected have less adverse effect on the performance of the collular manufacturing system than the single exceptional part in version 3. This is reflected in the value of Q I which increases to 0.92 from 0.90 in the previous case. Other neasures show detcrioration in grouping efficiency (Fig. $6(b)$ ). The performance measures in this version (Fig. $6(b)$ ) show improvement which is consistent with the increase in QI. 


\begin{tabular}{|c|c|c|c|c|c|c|c|c|c|c|c|c|}
\hline & & & & & & & ar & & & & & \\
\hline & & 1 & 2 & 6 & 9 & 3 & 7 & 11 & 4 & 5 & 8 & 10 \\
\hline $\mathrm{M}$ & 2 & 1 & 1 & 1 & 1 & & & & & & & \\
\hline $\mathrm{a}$ & 3 & 1 & 1 & 1 & 1 & & & & & & 1 & \\
\hline $\mathrm{c}$ & 1 & & & & & 1 & 1 & 1 & & & & \\
\hline $\mathrm{h}$ & 5 & & & & & 1 & 1 & 1 & & & & \\
\hline i & 6 & & & & & 1 & 1 & 1 & & & & \\
\hline$n$ & 4 & & & & & & & & 1 & 1 & & 1 \\
\hline$c$ & 7 & & & & & & & & 1 & 1 & 1 & 1 \\
\hline
\end{tabular}

(a) Block diagonal form.

\begin{tabular}{|c|c|c|c|c|}
\hline \multicolumn{5}{|c|}{ Matrix efficiency } \\
\hline$B E$ & GE & $\mathrm{GC}$ & GiCl & QI \\
\hline 0.90 & 0.97 & 92 & 0.96 & 0.99 \\
\hline & \multicolumn{3}{|c|}{ Shop performance } & \\
\hline \multicolumn{2}{|c|}{$\begin{array}{l}\text { Flow time } \\
78\end{array}$} & \multicolumn{3}{|c|}{$\begin{array}{c}\text { Work-in-progress } \\
40\end{array}$} \\
\hline
\end{tabular}

(b) Grouping measures and simulation results.

Figure 5. Version 3 of the machine-component matrix.

Finally, in version 5, two exceptional elements were created (Fig. $7(a)$ ) but in this case the two operations with the largest workload contents are relocated (operations of part 6 on machine 2 and part 4 on machine 7). It was expected that the heavier intercellular workload created by these two new exceptional elcments would lead to further deterioration in shop performance. The results of the sinulation runs show a drastic change in all performance measures (Fig. 7(b)). QI criteria performed accordingly and showed a drop in efficiency of the matrix from 0.96 to 0.78 . All other measures showed no change in efficiency in spite of change in shop performance.

\subsection{Graphical comparison of results}

Based on the results obtained by the five versions of machine-component matrix. the values of efficiency measures versus the shop performances are plotted in Fig. 8. As this figure illustrates, the mean flow time increases as the efficiency of machinecomponent matrix decreases. The graph of QI consistently follows such a relationship while $\mathrm{GE}, \mathrm{GC}, \mathrm{GCI}$ and $\mathrm{BE}$ have a mixed pattern.

\subsection{Test of hypothesis}

To draw a statistical conclusion on goodness of proposed QI measure a test of hypothesis was conducted which is defined as follows:

$\mathrm{H}_{\mathrm{ol}}$ : No difference exists, between mean flow time at different levels of QI.

$\mathrm{H}_{\mathrm{o} 2}$ : No difference exists, between mean work-in-process (WIP) inventory at a different level of QI. 


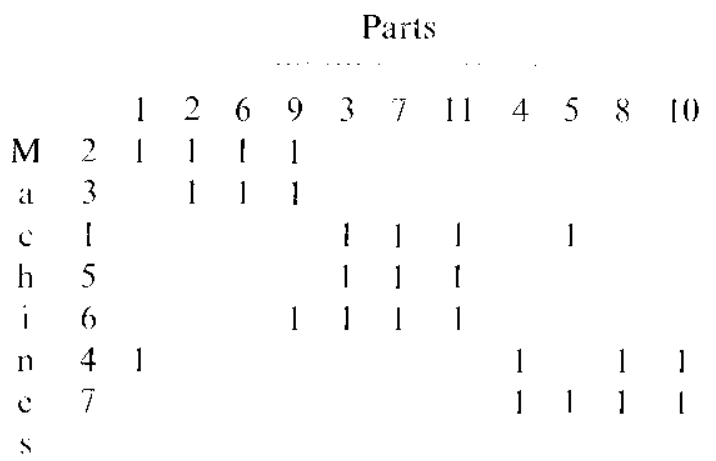

(a) Block diagonal form.

\begin{tabular}{|c|c|c|c|c|}
\hline \multicolumn{5}{|c|}{ Matiix efficiency } \\
\hline $\mathrm{BE}$ & GE & $\mathrm{GC}$ & Gol & Q1 \\
\hline 0.84 & 0.04 & 0.85 & $(0.92$ & 0.92 \\
\hline \multicolumn{5}{|c|}{ Shop perfornance } \\
\hline Flo & time & & $\begin{array}{c}\text { in-pro } \\
19\end{array}$ & \\
\hline
\end{tabular}

(h) Grouping measures and simalation results.

Figure 6. Version 4 of the machine component matrix.

Rejection of $H_{01}$ and $H_{02}$ implies that the poromance of cellulat natiofacturing is significantly sensitive to the change in eificioncy of machine-somponent matrix.

Tabk 1 shows the $95 \%$ confidence intervals of the steady state inean flow lime and WIP inventory for 5 cases under study.

From the table, the estimates of the neari llow time (F $F_{i}$ and trican WIP iriventories appear to be somewhat different from one version to another. To see il this diferenoc is statistically significant a paired-t test confidence interval (D)issemi 1994) was used and the results are summátized in fabies 2 and 3.

From Table? the wall hypothesis $\left(H_{0} 1\right)$ concerning ihe difference betweo version 1 and 2 in torms of mean fow time was accepted at the $5 \%$ level af significance. lo other words, these two versions have been very close in the job's intan flow times. Ithe efficiency of corresponding mochine-componcht matites in terms of QI were 1 and 0.99 respectively which explains the close performance of the 1 we versions.

The null hypothesis was rejected in the remaining cass; indicating that means flow times were not equal between versions 2 and 3,3 and 4 , anc 4 and 5 . There is an explanation for this iszalt. That is, changes in QI level have a significant inipact on mean flow time while changes in other effeicney ineasures did not show the same efrect and even in some cases did not show any efrect.

Table 3 shows the results of the test of hypothesis on WIP inventory. The inferences of the results led to acceptance of null hypothesis $H_{o}$ ? concerining the mean difference beween version 1 and 2 in terms of Wy?. When the QI level risianined unchanged from version I to version 2 , the shop porformance reacted correctly. That is, WIP inventory remained unchanged. The null hypothesis for mican difierence of 


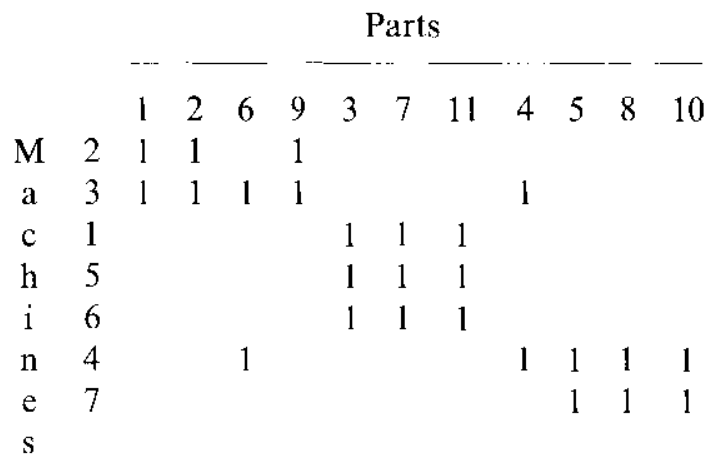

(a) Block diagonal form.

\begin{tabular}{|c|c|c|c|c|}
\hline \multicolumn{5}{|c|}{ Matrix efficiency } \\
\hline $\mathrm{BE}$ & GE & $\mathrm{GC}$ & $\mathrm{GCI}$ & Ql \\
\hline 0.84 & $0 \cdot 94$ & $0 \cdot 85$ & 0.92 & 0.78 \\
\hline \multicolumn{5}{|c|}{ Shop performance } \\
\hline $\begin{array}{r}\text { Flo } \\
67\end{array}$ & & Mcal & $\begin{array}{l}\text { rk-in } \\
3 \text { Par }\end{array}$ & gresis \\
\hline
\end{tabular}

(b) Grouping measures and simulation results.

Figure 7. Version 5 of the machine-component matrix.

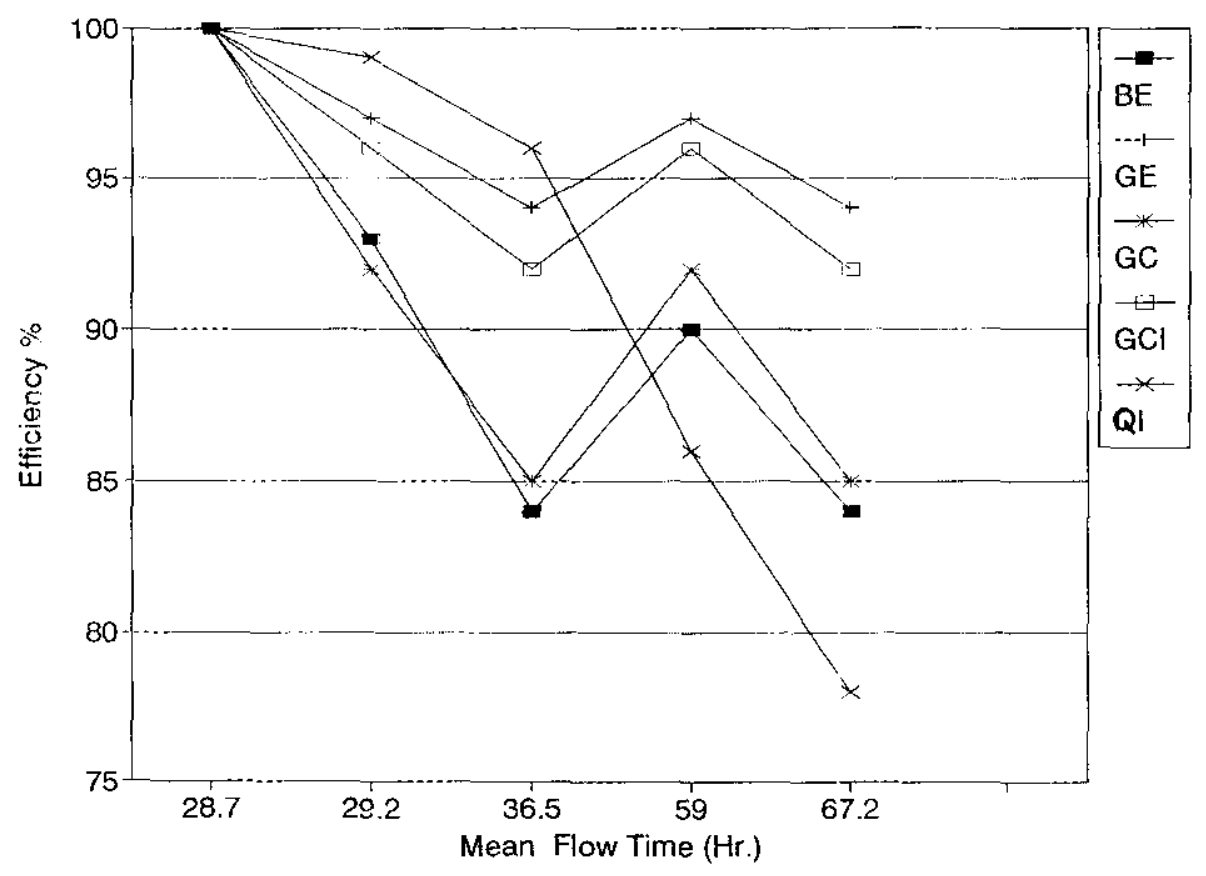

Figure 8. Valves of grouping measures versus mean flow time. 
versions 3 and 2,3 and 4,5 and 4 was rejected, indicating that the changes in Ql level has significant impact on mean WIP inventories in the cellular manufacturitig shops.

As expected, the above results indicate that only QI among the grouping measure: is sensitive to changes in workload content of parts in a cellular manufacturing system. Since workload content is more closely related to the perforimance of a cellular manufacturing system, $Q I$ is a more effective grouping efficiency measuite than other measures discussed in the literature. This is confirmed by simulation results which are consistent with QI values.

To provide a common basis for the comparison of grouping measures, a frequently cited machinc component matrix will be used to calculate different grouping measures and to generate the simulation results. The finat machincecomponent matrix with 16 machines and 43 parts is given in Fig. 9 (Burbidge 1977). The grouping measures and simulation results for this machinecomponont matrix and a modified form of it (in the modified form three enachines: 6,8 and 10 have been duplicated) are given in Fig. 10. The modified machine-component natrix is presented in Fig. 11. The results reinforce the conclusions drawn from the previous simple example and provide further support to the idea of using grouping measures for performance cvaluation in cellular manufacturing systems.

\begin{tabular}{|c|c|c|c|c|}
\hline $\begin{array}{l}\text { Matrix } \\
\text { version }\end{array}$ & $\begin{array}{l}\text { Mean fiow } \\
\text { lime }\left(F_{i}\right)\end{array}$ & $\begin{array}{c}C 1 \\
45 \%\end{array}$ & $\begin{array}{c}\text { Mean } \\
\text { WIP(W }\left(W_{i}\right)\end{array}$ & $\begin{array}{l}\mathrm{Ci} \\
95 \%\end{array}$ \\
\hline 1 & $28 \cdot 7$ & $22.7 \quad 34.6$ & $13 \cdot 2$ & $0.05 \cdot 17.7$ \\
\hline 2 & $29 \cdot 2$ & $23 \cdot 4 \quad 34 \cdot 9$ & $13 \cdot 4$ & $9 \cdot 29 \cdots 28 \cdot 5$ \\
\hline 3 & 59 & $41 \cdot 8 \quad 77 \cdot 3$ & 29 & $18.6 \quad 41.2$ \\
\hline 4 & $36 \cdot 5$ & $28 \cdot 8 \quad 44 \cdot 1$ & $17 \cdot 0$ & $12 \cdot 0.22 \cdot 1$ \\
\hline 5 & $67 \cdot 2$ & $47.3 \quad 87.0$ & 33 & $21 \cdot 9 \quad 44 \cdot 2$ \\
\hline
\end{tabular}

Table 1. Means and confidence intervals of llow time atid WIP.

\begin{tabular}{ccc} 
Mean difference & CI, 95\% & Test of hypothesis \\
$F_{2} F_{1}$ & $0 \cdot 512+0 \cdot 531$ & Acept $H_{01}$ \\
$F_{3} \cdot F_{4}$ & $30 \cdot 4.17 .5$ & Reject $H_{01}$ \\
$r_{3} \cdot F_{4}$ & $23 \cdot 1 \pm 15 \cdot 2$ & Reject $H_{01}$ \\
$F_{5} \cdot F_{4}$ & $30 \cdot 7 \pm 19.3$ & Reject $H_{01}$ \\
\hline
\end{tabular}

Table 2. Results of test of hypothesis for inean flow time.

\begin{tabular}{ccc}
\hline Mean diffcrence & Cl, $95 \%$ & Test of hypothesis \\
$\mathrm{W}_{2} \cdot \mathrm{W}_{1}$ & $0 \cdot 167+0.232$ & Acopi $\mathrm{H}_{02}$ \\
$\mathrm{~W}_{3} \mathrm{~W}_{2}$ & $16 \cdot 7 \pm 8 \cdot 62$ & Reject $\mathrm{H}_{02}$ \\
$\mathrm{~W}_{3} \mathrm{~W}_{4}$ & $3 \cdot 84+2 \cdot 34$ & Reject $\mathrm{H}_{02}$ \\
$\mathrm{~W}_{5} \cdot \mathrm{W}_{4}$ & $19 \cdot 8 \pm 8.81$ & Reject $\mathrm{H}_{02}$ \\
\hline
\end{tabular}

Table ?. Results of test of hypothesis for mean Wi?. 


\section{Parts}

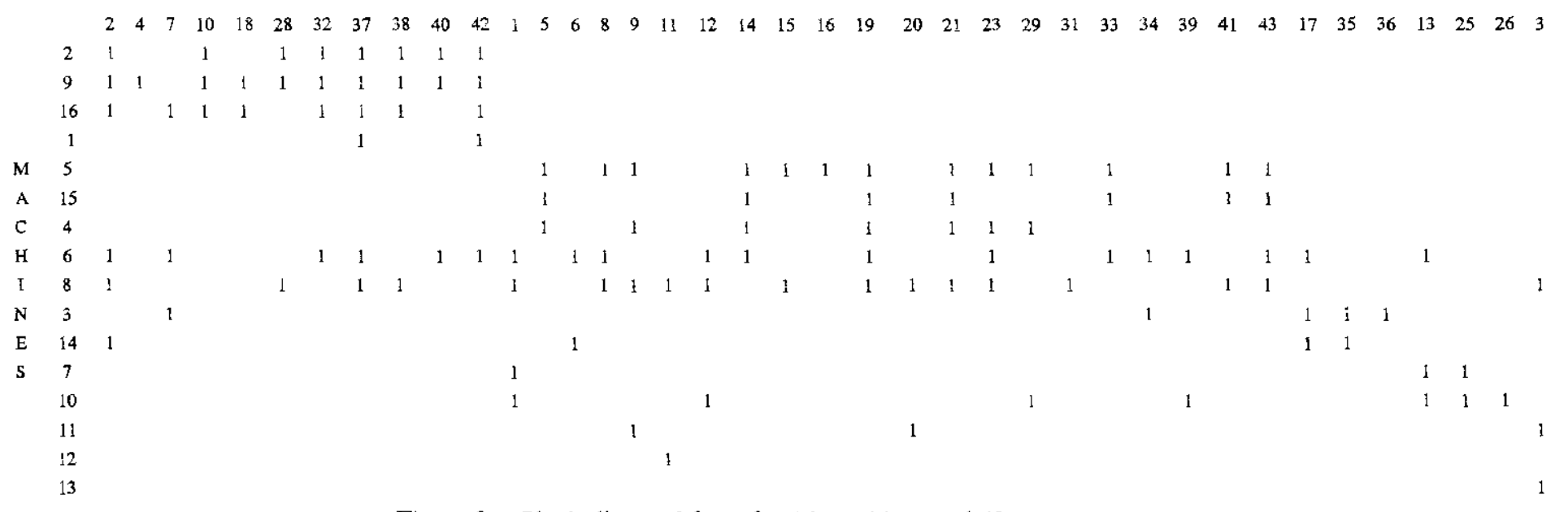

Figure 9. Block diagonal form for 16 machines and 43 parts.

\begin{tabular}{|c|c|c|c|c|c|c|c|}
\hline Case & GE & $\mathrm{GC}$ & GCI & $\mathrm{BE}$ & QI & Flow time & WIP \\
\hline 1 & 0.73 & 0.45 & 0.78 & 0.80 & 0.61 & $21 \mathrm{Hr}$. & 17 \\
\hline 2 & 0.75 & 0.46 & 0.90 & 0.82 & 0.86 & $20 \mathrm{Hr}$. & 13 \\
\hline
\end{tabular}

Figure 10. Efficiency and performance measures for Burbidge's problem. Case 1. Cellular manufacturing without machine duplication.

Case 2. Cellular manufacturing with machine duplication. 


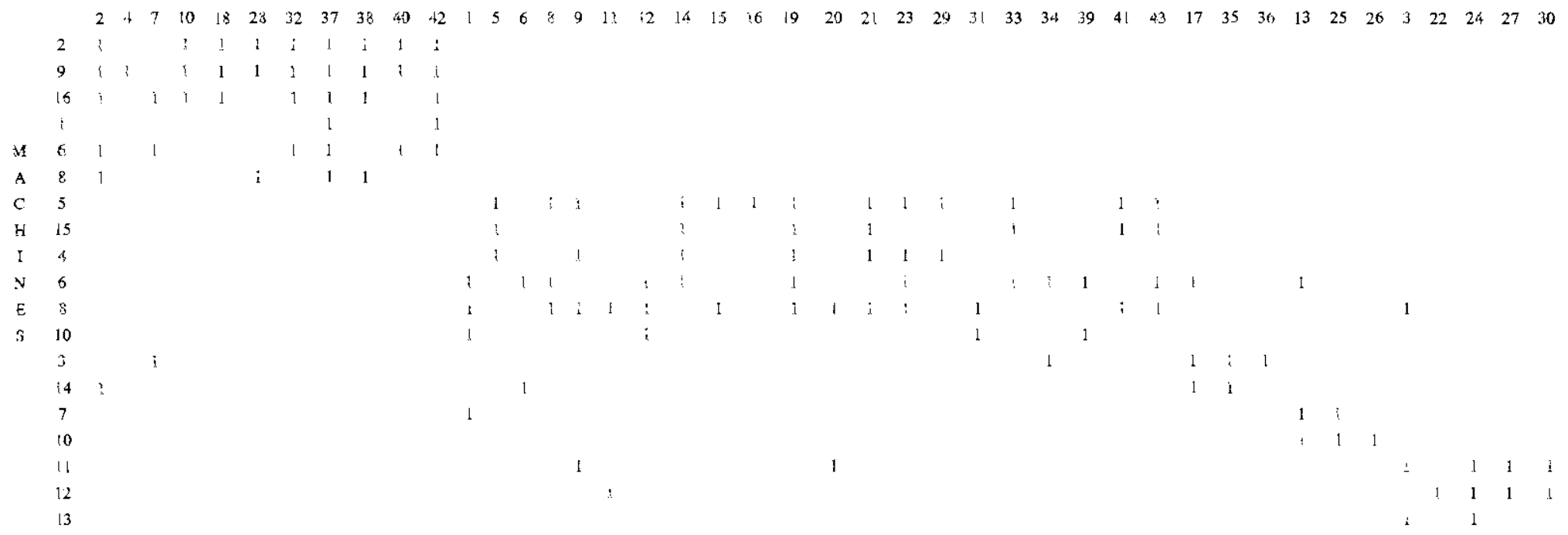

Figure 11. Machine-cotrponen matrix with ibree mactines duplicaled, 


\section{Conclusions}

Simulation modelling was used to determine the relationship between values of grouping measures and the performance of the corresponding cellular manufacturing system. Five different grouping measures were compared based on the simulation results. The study shows that grouping measures when properly defined can predict the performance of the corresponding cellular manufacturing system. Based on the simulation results, the newly defined grouping measure, QI, is more effective than other measures because it is more closely related to the performance of the cellular manufacturing system.

\section{References}

Burbidge, J. L., 1977. A manual method of production flow analysis. The Production Engineer, 56(1), 34 .

Carrie, A. S., 1973, Numerical taxonomy applied to group technology and plant layout. International Journal of Production Research, 11(4), 399--416.

Cнu, C. H., and Tsı, M., 1991, A comparison of three array-based clustering techniques for manufacturing cell formation. Intomational Journal of Production Research, 28, 1417 1433.

Chan, H. M., and Milni:R, D. A., 1982, Direct clustering algorithm for groups formation in cellular manufacturing. Journal of Manufacturing System.s, 1(1), 65-74.

Chandrasekiharan, M. P., and Rajagopalan, R., 1987, ZODlaC ‥ An algorithm for concurrent formation of part families and machine cells. Internctional Journal of Production Research, 25(6), 835850.

Diassemi, M., 1994. The use of machine-grouping efficiency in comparison of job-shop and cellular manufacturing systems: a simulation study. PhD thesis, University of Wisconsin Milwaukee.

Hsu, C. P., 1990, Similarity coefficient approaches to machine-component cell formation in cellular manufacturing: a comparative study. PhD thesis, Industrial and Systems Engineering, University of Wisconsin Milwaukee.

KING, J. R., and NAKORNCHAI, V., 1982, Machine-component group formation in group formation in group technology Review and Extension. International Journal of Production Research, 117-133.

Kumar, C. S., and Cilandrastekiaran; M. P., 1990, Grouping efticacy: a quantitative oricntation for goodness of block diagonal forms of binary matrices in group technology. International Journal of Production Research, 28(2), 233-243.

Law, A. M., and Kelron, W. D., 1982, Simulation Modeling and Analysis (New York: McGraw-Hill).

McAuli: , J., 1972, Machine grouping for efficient production. Production Engineering, 51, February, 5357.

McCormick, W. T., Schwertytr, P. J., and Whrrk, T. W., 1972, Problem decomposition and data reorganization by a clustering technique. Operations Research, 52, February, 9931009 .

Miltevhurg, J., and Zilang, W., 1991, A comparative cvaluation of nine well-known algorithms for solving the cell formation problem in group technology. Journal of Operations Management, 10(1), 4472.

Mosife, C. 'T', 1989, An experiment investigating the application of clustering procedures and similarity coefficient to GT machine cell formation problems. International Journal of Production Research. 27, 1811-1935.

SeIFoDmIN, H., and WOLFF, P. M., 1986, $\Lambda$ pplication of the similarity coefficient method in group technology. Transactions of the Institute of Industrial Engineers (IIE), 18(3), $271-$ 277.

Seifordini, H., 1989, Duplication process in machine cell formation in group technology. Transactions of the Institute of Industrial Engineers (IIE), 21(4), 382 -388. 